\title{
Non-voluntary passive euthanasia should be legalized in Sri Lanka
}

\author{
Vidanapathirana $M^{*}$
}

\begin{abstract}
Euthanasia is the practice of intentionally ending a life of another person to relieve pain and suffering. When the consent of the person is considered, it can be classified into voluntary, non-voluntary or involuntary, and based on the method of application, it is classified into active or passive euthanasia. Voluntary euthanasia can be performed at the time of the illness or in advance by way of "living wills". 'Involuntary euthanasia' is performed against the will of the patient and the physician takes the decision on his own. In 'non-voluntary euthanasia', the patient leaves the decision making capacity with a physician or a relation by proxy. If no prior proxy, a court order can be obtained. In 'active euthanasia', death is brought about by an act of commission and in 'passive euthanasia'; the death is brought about by an act of omission by the physician. However, none of these methods can be practised in Sri Lanka. Why 'non-voluntary passive euthanasia' should be legalized in Sri Lanka? To up hold the rights of the terminally ill and allow them to die with dignity. Otherwise, physicians misuse euthanasia and perform illegal and unethical malpractices such as 'Do not resuscitate (DNR) orders'. However, in 'non-voluntary passive euthanasia', the medical paternalism is minimal, because, 'proxy' is not directly related to ending of life, it is to take relevant decisions if incapacitate. Further, it is legalized in India, England, Albania, Hungary and many parts of the USA. Therefore, non-voluntary passive euthanasia should be considered for legalization in Sri Lanka.
\end{abstract}

Key words: Non-voluntary passive euthanasia, proxy, court order, Sri Lanka

\section{Full paper}

Euthanasia is the practice of intentionally ending a life of another person in order to relieve pain and suffering. ${ }^{[1]}$ Howeverthe general understanding of euthanasia is thebringing about of a good death or 'mercy killing', where one person ends the life of another person, for his or her sake. ${ }^{[1,2]}$ To justify such acts and circumstances, the ethical principles applied frequently are the "right to die" and "right to terminate life".

*Corresponding author:Vidanapathirana M, Department of Forensic Medicine, Faculty of Medical Sciences, University of Sri Jayewardenepura, Sri Lanka. Email: mudithavidana@sjp.ac.lk, Tel: 0094 772988227.

DOI: http://doi.org/10.4038/mljsl.v5i1.7346

https://orcid.org/0000-0003-0071-0996
Euthanasia is practised at different stages of life. At the 'beginning of life', it is practised in circumstances such as locked twins, where one child is killed by the obstetrician to facilitate the delivery of the other. 'During life', it is practised among the terminally ill or patients with incurable illnesses.

The terminally ill are the patients with no hope of recovery and are either fully conscious or deeply comatose.However, patients with incurable illness such as disseminated malignancy also have no hope of recovery but are not terminally ill. At the 'end of life', euthanasia is practised to achieve a 'death with dignity'.

Classification of euthanasia depends on several factors. When the consent of the person is considered, it can be classified in to three; voluntary, non-voluntary or involuntary, and based on the physician's involvement, it is classified into active or passive euthanasia.

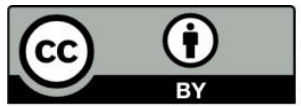

This is an open-access article distributed under the terms of the Creative Commons Attribution License, which permits unrestricted use, distribution and reproduction in any medium, provided the original author and source are credited. 
When a person knowingly declares the wish to end his life or specially requests that his life be terminated it is termed as voluntary euthanasia. ${ }^{[2]}$ This request may be made prior to the development of illness in way of 'living will' or 'advanced directive', or during the course of the illness.

When considering 'non-voluntary euthanasia', the patient leaves the 'decision making capacity' with a physician or a relation by proxy. ${ }^{[3]}$ The physician or relation makes the decision on his behalf upon the request of the patient. This is called "Suicide by proxy". Here, someone directly or indirectly ends another person's life, because they believe it is in their best interest in order to relieve pain and suffering from an incurable or terminal condition. If no prior proxy, relatives and physicians can take a court order to terminate life for the best interest of the patient and to die with dignity. This is practicedin instances of death of a patient for his own good, where the patient is unable to express any view on the matter, for example in patients who are in a permanent vegetative state. Therefore, this is also called 'Mercy killing'.

'Involuntary euthanasia' is performed against the will of the patient and the physician takes the decision on his own to terminate the life of the patient without a personal or proxy invitation and this amounts to homicide, whether active or passive. ${ }^{[4]}$

When considering 'active euthanasia', death is brought about by an act of commission by the physician. Here, the physician determines the date and time of the death of the patient. However, active euthanasia is unlawful and unethical. For example, in such circumstances, the physician injects Potassium chloride $(\mathrm{KCl})$ or a "Double effect drug" such as high dose of morphine, where both pain relief and respiratory suppression occur.

Whereas, in 'passive euthanasia', the death is brought about by an act of omission by the physician such as cessation of naso-gastric feeds, nursing care etc.

When voluntary euthanasia is considered separately, it can be further divided in two; voluntary passive and voluntary active euthanasia. Voluntary refusal of treatment or voluntary refusal of food and fluids(VRFF) by a patient is 'voluntary passive euthanasia' and it does not amount to homicide, because an adult patient with sound mind has the right to refuse treatment. ${ }^{[5]}$ This refusal can be done at the time of the illness or in advance by way of "living wills or advance directives". Further, physicianassisted suicides (PAS), are also a type of "voluntary passive euthanasia'. In this situation, a physician supplies information or the means of committing suicide to a person. For example, the physician supplies a prescription for a lethal dose of sleeping pills, so that the individual can successfully terminate his or her own life ${ }^{[6]}$ Some believe that patients with sound mind have the liberty and right to end their lives by adopting methods of all manners that do not involve physicians. However, the principle of "right to die" is a reward for the patient to utilize the "right to have a help of a physician to kill himself". ${ }^{[7]}$

In UK, in 1935, the British Voluntary Euthanasia Society (later known as "EXIT" and now as "Dignity in Dying")produced "A Guide To Self-Deliverance" giving guidelines on how a person should commit suicide. ${ }^{[4]}$ The publication was delayed amid controversy because of the UK Suicide Act of 1961 which states that the legal system can allow up to 14 years in prison for anyone that assists in suicide ${ }^{[4]}$ However, it is the Scottish branch (now called EXIT) that published 'How to Die with Dignity' in $1980,{ }^{[8]}$ became the first publication on physician-assisted suicide (PAS)in the world. ${ }^{[6]}$ The question among politicians in Britain today is why they force their citizens, people in the most terrible circumstances who are determined to end their suffering in a way of their own choosing, to leave their country and travel to Switzerland to exercise their free will? ${ }^{[6]}$

When considering PAS, Dr. Jack Kevokian, an American pathologist cannot be overlooked. He often appeared in the media as "Dr. Death" and publicly campaigned for terminal patient's right to die via physician-assisted suicide. He claimed to have assisted at least 130 patients to die and famously declared that "Dying is not a crime" ${ }^{[2]}$.However, in PAS, the physician should play a passive role rather than active,for in some instances, when they play an 
active role, it turns into 'voluntary active euthanasia', which is illegal and unethical. In 1999, Dr. Kevorkian was arrested and tried for his direct or active role in a case of voluntary euthanasia. He was convicted of second-degree murder and served eight years of prison sentence. ${ }^{[2]}$ Later, this story appeared in the film "You don't know Jack".

When non-voluntary euthanasia is considered individually, it can be further classified in to two groups: non-voluntary passive and non-voluntary active euthanasia.

Withdrawal of treatment in a terminally ill patient on proxy consent or court order is 'non-voluntary passive euthanasia'. Anthony David Tony Bland was an 18 year old supporter of Liverpool Football Clubwho got injured on $15^{\text {th }}$ April 1989, in the Hillsborough disaster, following a collapse of a pavilion. ${ }^{[9]}$ He suffered severe brain damage that left him in a persistent vegetative state for four years. The hospital, with the support of his parents, applied for a court order allowing him to 'die with dignity'. As a result, he became the first patient in English legal history to be allowed to die by the courts through the withdrawal of life-prolonging treatment. ${ }^{[9]}$

Non-voluntaryactive euthanasia is illegal in all countries in the world, although it is practised in the Netherlands,Belgium, Luxemburg and Switzerland. Infants with conditions such as severe hydrocephalus can be subjected to non-voluntary active euthanasia in the Netherlands if parents and doctors decide it is the best choice for their child. ${ }^{[12]}$

Involuntary euthanasia can be further divided into two groups; involuntary passive and involuntary active euthanasia.

The non-treatment of a treatable condition by leaving 'Do not resuscitate (DNR)orders' is 'involuntary passive euthanasia'. Since it is involuntary, it is unethical and also amounts to homicide ${ }^{[13]}$.

Further, involuntary active euthanasia is illegal in all countries in the world. However, in 2008, Shirley Justins and Caren Jennings were found guilty of manslaughter for providing a lethal dose of medicine to former pilot Graeme Wylie in 2006. Justins stated that Wylie wanted to "die with dignity". The prosecution argued that Wylie did not have the mental capacity to make the crucial decision to end his life, classifying it as involuntaryactive euthanasia and they were found guilty. ${ }^{[14]}$

In Tasmania, Australia, in 2005, a nurse was sentenced for two and half years for assisting the death of her elderly father, who had terminal cancer. ${ }^{[15]}$ However, the judge later suspended the conviction because he believed that the community did not want the woman jailed. This sparked the debate about decriminalizing euthanasia. ${ }^{[10]}$

In contrast, human euthanasia has been criminalized in Mexico, Thailand and the Northern Territory of Australia too. ${ }^{[2]}$ Further, none of these methods of euthanasia, whether active or passive, can be practised in Sri Lanka.

Why euthanasia should be legalized in Sri Lanka? It is to uphold the rights of the terminal ill patients to die with dignity. Otherwise, physicians misuse euthanasia and perform illegal and unethical malpractices such as DNR orders misusing medical paternalism. It is a type of involuntary passive euthanasia and the physician orders not to resuscitate if patient goes into cardiac arrest. Since it is involuntary, it amounts to homicide.

Voluntary passive euthanasia (eg. PAS) is legal in Switzerland, Germany, Japan, Albania and some US states (Washington, Oregon, Vermont, New Mexico, Montana, and California). ${ }^{[2]}$ However, why we should not legalize PAS in Sri Lanka? Because, the doctors can misuse it. Doctors can end the lives of patients after making a false judgment that their lives are of no value and claim that they are simply acting in their patients' best interests. This is called medical paternalism. $^{[15]}$

Since active euthanasia is illegal and unethical, voluntary active euthanasia cannot be considered for legalization. Further, it is illegal in all the countries. 
Non-voluntary active euthanasia is legalized only in the Netherlands, Belgium, Luxemburg and Switzerland. (Netherlands on infants under an agreement between physicians and district attorneys). ${ }^{[16]}$ Since active euthanasia is illegal and unethical it cannot be considered for legalization.

Involuntary passive euthanasia such as DNR orders are being practised. Since it is involuntary, it is illegal and unethical and cannot be considered for legalization.

Involuntary active euthanasia is illegal in all the countries in the world and is the worse form of euthanasia because both involuntariness and active involvement are illegal and unethical and cannot be considered for legalization.

Therefore, euthanasia represents a frequently disputed medical, ethical, legal and social issue worldwide. The concept of non-voluntary passive euthanasia is being debated endlessly. Len Doyal, a professor of medical ethics stated that "non-voluntary passive euthanasia should be legalized under appropriate circumstances and with proper regulations". ${ }^{[9]}$ Arguing against legalization, Peter Saunders, the campaign director for 'Care, Not Killing', called Doyal's proposals as "the very worst form of medical paternalism whereby doctors can end the lives of patients after making a judgment that their lives are of no value and claim that they are simply acting in their patients' best interests". ${ }^{[15]}$

However, in non-voluntary passive euthanasia, medical paternalism is minimal. Because it is done on patient's proxy consent and proxy is not directly related to ending life and it is the decision making capacity if incapacitate. When it is written to doctors, decisions are taken for the best interest of the patient. If a prior proxy is not available, relatives and physicians should take a court order to stop medical management for the best interest of the patient and to die with dignity. Therefore, it is legalized inIndia (2011) ${ }^{[10]}$ England, Albania, Hungary and many parts of the United State. ${ }^{[9]}$

On $7^{\text {th }}$ March 2011, the Supreme Court of India legalized non-voluntary passive euthanasia by means of the withdrawal of life support to patients in a permanent vegetative state. The decision was made as part of the verdict in a case involving ArunaShanbaug, who had been in a Persistent Vegetative State (PVS) until her death in the year 2015. ${ }^{[11]}$ Therefore, in such instances, especially in the countries where passive euthanasia is not legalized, similar to the Tony Bland case, it is justifiable to obtain a court order.

In conclusion, to prevent illegal unethical practice of euthanasia, non-voluntary passive euthanasia should be considered for legalization in Sri Lanka.

Note: Some contents of this article were published in newsletter of SLMA in June 2016.

\section{References}

1. Philosopher Helga Kuhse: "'Euthanasia' is a compound of two Greek words - eu and thanatos meaning, literally, 'a good death'. [Cited 2016 Jan 23]. Available from: http://www.worldrtd.net/euthanasia-fact-shee.

2. Gajic V. Euthanasia through history and religion. Medicinski Pregled 2012 MarApr;65(3-4):173-7.

3. Mercy killing facts. [Cited 2016 Jan 25]. available from: http://www.buzzle.com/articles/ mercy-killing-facts.html

4. Whiting R. A Natural Right to Die: TwentyThree Centuries of Debate. Westport: Connecticut; 2002. p. 41.

5. Harvath TA, Miller LL, Goy E, Jackson A, Delorit M, Ganzini L. Voluntary refusal of food and fluids: attitudes of Oregon hospice nurses and social workers. Int J Palliat Nurs. 2004 May;10(5):236-41; discussion 242-3.

6. McDougall, JF, Gorman M. Contemporary World Issues: Euthanasia. Santa Barbara, California: ABC-CLIO; 2008. pp. 70-73.

7. Yang YT, Curlin FA. Why Physicians Should Oppose Assisted Suicide. JAMA 2016 Jan 19;315(3):247-8.

8. Mair GB. How to Die with Dignity. Edinburgh, Scotland: Scottish Exit; 1980.

9. Tony Bland. [Cited 2016 Jan 23] Available from: https://en.wikipedia.org/wiki/Tony _Bland. 
10. Shukla R. Passive euthanasia in India: a critique. Indian Journal of Medical Ethics 2015; $5(-): 1-4$.

11. "Common Cause (A Regd. Society) v. Union of India - (2014) 5 SCC 338 [Euthanasia reference to Constitution Bench]". [Cited 2016 Jan 23] Available from: https://en. wikipedia.org/wiki/Euthanasia_in_India.

12. "Ending the Life of a Newborn: The Groningen Protocol,: Introduction". [cited 2016 Jan 24] Available from: www.medscape.com.

13. What is DNR order.[cited 2016 Jan 24] Available from: http://euthanasia.procon.org /view. answers.php? questionID=000188.
14. Issues backgrounder, New South Wales, parliamentary Library, May 3013. Page.14. [Cited 2016 Jan 24] Available from: https ://www.parliament.nsw.gov.au/Euthanasia+Issu es+Backgrounder+.

15. Non-voluntary euthanasia. [Cited 2016 Jan 24] Available from: http://research. omicsgroup.org/index.php/Non-voluntary _euthanasia.

16. Chao DV, Chan NY, Chan WY. Euthanasia revisited. Family Practice 2002 Apr;19(2):12834. 